\title{
Mutagenicity Assessment of Drinking Water in Combination with Flavored Black Tea Bags: a Cross Sectional Study in Tehran
}

\author{
Farzaneh Alebouyeh ${ }^{1}$, Sepideh Arbabi Bidgoli, Parisa Ziarati ${ }^{3}$, Masoomeh \\ Heshmati $^{4}$, Mahnaz Qomi ${ }^{1}$
}

\begin{abstract}
Diseases related to water impurities may present as major public health burdens. The present study aimed to assess the mutagenicity of drinking water from different zones of Tehran, and evaluate possible health risks through making tea with tea bags, by Ames mutagenicity test using TA 100, TA 98 and YG1029 strains. For this purpose, 450 water samples were collected over the period of July to December 2014 from 5 different zones of Tehran. Except for one sample, no mutagenic potential was detected during these two seasons and the MI scores were almost normal ( $\leq 1-1.6)$ in TA 100, TA 98 and YG1029 strains. Although no mutagenic effects were considered in TA 98 and TA 100 in the test samples of our three evaluated tea bag brands, one sample from a local company showed mutagenic effects in the YG1029 strain (MI=1.7-1.9 and 2) after prolonged (10-15 min.) steeping. Despite the mild mutagenic effect discovered for one of the brand, this cross sectional study showed relative safety of water samples and black tea bags in Tehran. According to the sensitivity of YG1029 to the mutagenic potential of water and black tea, even without metabolic activation by $s 9$ fraction, this metabolizer strain could be considered as sensitive and applicable to food samples for quantitative analysis of mutagens.
\end{abstract}

Keywords: Drinking water - tea bags - Ames test - mutagenicity - Tehran, Iran

Asian Pac J Cancer Prev, 16 (17), 7479-7484

\section{Introduction}

Drinking water is one of the most important public health issues which is associated with different healthrelated concerns (Abda et al., 2015). These concerns are divided to microbial and chemical pollutants, which are completely described in the international guidelines for drinking water quality (Karyab et al., 2013). Many studies have emphasized a basis for health risk assessment of drinking water to strength current authorities and reduce the possible health risks arising from trace-level hazardous pollutants in drinking waters (Bain et al., 2014). Tehran the capital city of Iran is a highly polluted city and the concentration of contaminants in air, drinking water and other environmental resources varies according to the geographical location, season (Ziarati et al., 2012) and many other factors (Karyab et al., 2013).

Diseases related to food (Punvittayagul et al., 2014), and water impurities have been considered as major public health burdens and the causal relationship between cancer incidence especially gastric cancer (Zhao et al., 2014) from a wide range of impurities (Kumari et al.,
2015), congenital malformations through disinfectant contaminations (Villanueva, 2014), endocrine disruptions (Bidgoli et al., 2012) through pesticide residues (Dhaini et al., 2014 and many adverse health effects in children by exposure to contaminated drinking water have been reported recently (Ileka-Priouzeaua et al., 2015).

On the other hand, widely used purification methods of water like $\mathrm{H}_{2} \mathrm{O}_{2}$ and chlorination may cause formation of carcinogenic disinfection by-products (DBPs) because of the intensified pollution of water supplies to organic matters (Villanueva et al., 2014). In fact these widely used methods for disinfection of drinking water (Kusamaran et al., 2003) are responsible for more than half of positive Ames mutagenicity assessments in apparently purified waters (Jansson et al., 1993), (Wright et al., 2002). For these reasons cross sectional analysis of genotoxic and mutagenic compounds in drinking water by a battery of genotoxic methods has been considered recently (Abda et al., 2015).

After drinking water, black tea is the most popular nonalcoholic beverage (Graham et al., 1992) in eastern countries including Iran but some recent local studies

${ }^{1}$ Pharmaceutical Sciences Research Center, ${ }^{2}$ Department of Toxicology and Pharmacology, Faculty of Pharmacy, ${ }^{3}$ Department of Medicinal Chemistry \& Pharmaceutical Sciences Research Center, ${ }^{4}$ Department of Molecular and Cellular Sciences, Faculty of Advanced Sciences and Technology, Islamic Azad University, Pharmaceutical Sciences Branch (IAUPS), Tehran, Iran *For correspondence: arbabi@iuaps.ac.ir 
have shown the existence of toxic elements in fresh or dried tea leaves as well as in brewed tea (Rezaee et al., 2014). Iranian people used to drink tea by traditional style but due to life westernaliztion using tea bags has become more usual especially in public areas and in industrialized cities (Pouretedal et al., 2013) like Tehran. Although the health benefits of the varieties of tea are widely perused, analysis of the potential toxicities of tea bags through possible impurities and colorants which may pose adverse effects on human health has been remained extensively ignored therefore it seems necessary to assess the possible mutagenic effects of tap waters as well as their combination with tea bags as one of the most widely used beverage in Iranian population as an initial screening test.

The main objective of the present study was to investigate the mutagenic potentials of drinking water from different zones of Tehran, to compare two most polluted seasons (summer and autumn) (Ziarati et al., 2012) and its combinational mutagenic effects with highly consumed flavored black tea bags in Tehran, the capital of Iran by Ames mutagenicity assessment which has been considered as a rapid, cheap, predictive and reliable method (Rincon-Bedoya et al., 2013).

\section{Materials and Methods}

\section{Water sampling}

Based on drinking water supply, Tehran has been divided to five zones. Three water samples were collected from each zone in two seasons over the period from July 2014 to December 2014 (i.e. a total of 450 samples) and each sampling was repeated three times from each zone with regular intervals. Sampling was performed according to ISO standard method guideline (Anon, 2006) and in order to prevent unwanted reactions, samples were collected in $500 \mathrm{~mL}$ amber glass bottles with Teflon lined tops. Each sample was stored in a cooler at $4^{\circ} \mathrm{C}$ while being transported to the laboratory water samples. The water bottles were autoclaved at $121^{\circ} \mathrm{C}$ for 20 minutes before the sampling and stored at $4^{\circ} \mathrm{C}$ for sample collection up to 1 week. All test tubes had been previously washed with distilled water and were placed at oven in $180^{\circ} \mathrm{C}$ for 2 hours. For the preparation of water samples, $10 \mathrm{~mL}$ of each water sample was poured into a test tube.

\section{Tea bag samples}

Out of different tea bag brands in the market of Tehran, three different batch numbers of three most widely used black tea bags was selected for present study.

Sample A: Sample A was a flavored tea which was produced by a company in London and purchased in Tehran's Market. Each tea bag contained six of the world's finest black teas on the basis of company's claim.

Sample B: According to the company's claim, this Iranian tea bag brand was prepared from highest quality of Indian tea with suitable fragrance and flavor with an easy method of usage. Type of envelop was single and double layer for more coloring and higher speed.

Sample C: According to the company's claims, it was the first producer of tea bags worldwide. This English black tea bag was full of color and taste too.

\section{Tea making by tea bags and tap water}

All tea samples were prepared under normal house preparation method. Packs of tea bags contained $3 \mathrm{~g}$ of ground black with particle sizes of $1-2 \mathrm{~mm}$. They were steeped in drinking water which was already boiled in $100 \mathrm{~mL}$ beakers. This conventional method of tea preparation helped us to study the effects of steeping times on mutagenic effects of tea infusions. In fact each tea bag put in each of the 3 beakers and infused for 5 minutes. Similarly, tea infusions with 10 and 15 minutes brewing time were prepared in triplicate for all the 3 black tea bags brands.

\section{Salmonella strains}

The Salmonella Typhymurim strains used in this study were TA100, TA98 and YG1029 a bacterial O-acetyltransferase-overproducing strain of TA100 (Sato G, 2000). The YG1029 was cloned and its activity was first described and established by T Nohmi and colleagues (Watanabe, 1994) who provided all strains as gift, from Biological Safety Research Center co., Ltd in TokyoJapan (2013).

\section{Bacterial reverse mutation assay}

The pre-incubation Ames assay was performed according to the method of OECD 471. Before starting the main experiments, the mentioned strains were checked for their genetic integrity by histidine/biotin dependence, histidine dependence, biotin dependence, rfa marker( crystal violet) and the presence of plasmid pKM101 (Ampicillin resistance) tests (Kumar et al., 2011). During all these preliminary experiments, the strains were grown overnight in nutrient broth for 16-18h in incubator at $37^{\circ} \mathrm{C}$ with a density of $1-2 \times 10^{8}(\mathrm{CFU}) / \mathrm{ml}$ in presence of $25 \mu \mathrm{g} / \mathrm{ml}$ Ampicillin for TA98,TA100 and $10 \mu \mathrm{g} / \mathrm{ml}$ Tetracycline for YG1029). The top agar was supplemented with histidine/biotin and prepared by dissolving $0.6 \mathrm{~g}$ of agar-agar and $0.6 \mathrm{~g} \mathrm{NaCl}$ in $100 \mathrm{ml}$ distilled water. A sterilized aqueous solution of L-histidine and D-biotin $(0.5 \mathrm{mM} / \mathrm{L})$ was added to top agar medium immediately before applications (Kumar et al., 2011), (Mortelmans $\mathrm{K}$ et al., 2000). In the next step, $100 \mu \mathrm{l}$ of overnight cultured bacteria with concentration of $1-2 \times 10^{8} \mathrm{CFU} /$ $\mathrm{ml}$ were incubated at $37^{\circ} \mathrm{C}$ for $45 \mathrm{~min}$ in a sterile glass tube containing $500 \mu$ lit sodium phosphate buffer $(0.1 \mathrm{M}$, $\mathrm{pH7.4)}$ with the different water and tea+ water samples. After incubation, $2 \mathrm{ml}$ of Top agar supplemented with histidine/biotin (kept in $45^{\circ} \mathrm{C}$ water bath) and added to the mixture and mixed for $3 \mathrm{~s}$ using a vortex mixer, then poured on a plate of minimal glucose agar media (Mortelmans, 2000). Plates were incubated for $48-72 \mathrm{~h}$ at $37^{\circ} \mathrm{C}$ and the revertant colonies were counted. Three equal plates were used for each sample and each experiment was repeated three times to get maximum accuracy and reproducibility for this sensitive method.

Ames test was repeated 3 times for each sample and at least 2 independent experiments were carried out to confirm the outcomes (Pongpiachan et al., 2013). Sodium azide was used as positive control for TA100 and YG1029 strains and 2-Nitrofluorene for TA98 strain. Distilled-deionized water was used as negative control 
for all of the samples. Genetic analysis of tester strains including genetic integrity and spontaneous mutation rate was performed regularly during the preparation of frozen cultures and after each experiment.

\section{Data Analysis}

For the Ames mutagenicity assay, positive responses required a dose-related increase in the number of revertant colonies/plate for each of strains and sodium azide at $5 \mu \mathrm{g} /$ ml concentration (Sigma Aldrich, cat number: 438456) was used as positive control. Negative response was defined as no concentration related increase in the number of revertant colonies and distilled water was used as negative control in this study. Also, a positive control was defined as an agent with defined concentration which can double the number of revertant colonies/plate in comparison to the vehicle control (Yan et al., 2012). The Mutagenic Index

Table 1. The Relationship Between Mutagenic Index (M.I.) Ranges and Mutagenic Potential of Samples Was Considered for Data Anaysis

\begin{tabular}{|c|c|}
\hline Ames test result & $\begin{array}{c}\text { Mutagenic Index (M.I.) } \\
\text { *range }\end{array}$ \\
\hline $\begin{array}{c}\text { No mutagenic potential is } \\
\text { assumed }\end{array}$ & $\leq 1-1.6$ \\
\hline $\begin{array}{c}\text { A possible mutagenic potential } \\
\text { is assumed }\end{array}$ & $1.7-1.9$ \\
\hline $\begin{array}{c}\text { A mutagenic potential is } \\
\text { assumed }\end{array}$ & $\geq 2$ \\
\hline
\end{tabular}

*Mutagenic Index (M.I.) = (The number of revertant colonies in the sample plate )/(The number of colonies in the negative control plate )
(M.I.) was described for each assay and calculated as the ratio between number of histidine revertants induced per plate of the test sample and spontaneous revertants of the negative control (Lupi, 2009). Details on data analysis method has been described in table 1 .

Statistical analysis was performed using IBM SPSS statistics software version 20 and one-way ANOVA(LSD) was used to compare the colony counts of each plate in different concentrations and groups. Multifactorial analysis was carried out by considering the concentration as the main factor and p-values $<0.05$ was considered as statistically significant changes.

\section{Results}

Mutagenic potentials of drinking water samples by Ames test

At first the mutagenic potentials of summer samples from 5 zones ( 225 samples in total) were analyzed in three equal intervals on three different strains. The Mutagenic Index (M.I.) was calculated for each assay and compered with negative control. The MI score was normal in all bio assays on TA 100, TA 98 and YG1029 strains in the summer 2014 and none of the water samples were considered as mutagen in the summer (Table 2). Details on TA100 and WG1029 bioassays were not showed.

In the next level, the mutagenic potentials of autumn samples from 5 different zones of Tehran were analyzed in three equal intervals on three different strains (225 samples in total). The Mutagenic Index (M.I.) was calculated for each assay and compered with negative control. The MI score was normal in all bio assays on TA 100, TA 98 and

Table 2. Ames Mutagenicity Assessment on Drinking Water Samples of Summer (TA98 strain)

\begin{tabular}{|c|c|c|c|c|c|c|c|}
\hline M.I3 & $\begin{array}{l}\text { Number of His+ } \\
\text { revertants/plate in } \\
\text { 3th test }\end{array}$ & M.I2 & $\begin{array}{l}\text { Number of His+ } \\
\text { revertants/plate in } \\
\text { 2end test }\end{array}$ & M.I1 & $\begin{array}{l}\text { Number of His+ } \\
\text { revertants/plate in } \\
1 \text { st test }\end{array}$ & Zones & Sample \\
\hline & $>800$ & & $>800$ & & $>800$ & & P.C \\
\hline & 362 & & 89 & & 82 & & N.C \\
\hline 1.05 & 382 & 1.08 & 97 & 0.87 & 72 & & 1 \\
\hline 0.83 & 300 & 0.84 & 75 & 0.87 & 72 & 1 & 2 \\
\hline 0.97 & 351 & 0.96 & 86 & 0.72 & 59 & & 3 \\
\hline 0.99 & 361 & 0.64 & 57 & 0.47 & 39 & & 4 \\
\hline 1 & 363 & 1.25 & 112 & 0.9 & 74 & 2 & 5 \\
\hline 0.9 & 326 & 1 & 89 & 0.76 & 63 & & 6 \\
\hline 0.74 & 269 & 0.84 & 75 & 0.68 & 56 & & 7 \\
\hline 0.75 & 271 & 0.57 & 51 & 0.6 & 50 & 3 & 8 \\
\hline 0.68 & 247 & 0.76 & 68 & 0.92 & 76 & & 9 \\
\hline 0.85 & 307 & 0.77 & 69 & 0.8 & 66 & & 10 \\
\hline 0.93 & 336 & 0.79 & 71 & 1.34 & 110 & 4 & 11 \\
\hline 1 & 362 & 0.89 & 80 & 0.96 & 79 & & 12 \\
\hline 0.97 & 351 & 0.73 & 65 & 0.84 & 69 & & 13 \\
\hline 1.02 & 371 & 0.76 & 68 & 1.03 & 85 & 5 & 14 \\
\hline 0.97 & 352 & 0.84 & 87 & 1.02 & 84 & & 15 \\
\hline
\end{tabular}

C: Positive Control N.C: Negative Control; *Mutagenic Index (M.I.) = (The number of revertant colonies in the sample plate $) /($ The number of colonies in the negative control plate ) 
Farzaneh Alebouyeh et al

Table 3. Ames mutagenicity assessment on drinking water samples of authumn (TA98 strain)

\begin{tabular}{|c|c|c|c|c|c|c|c|}
\hline M.I3 & $\begin{array}{l}\text { Number of His+ } \\
\text { revertants/plate in } \\
\text { 3th test }\end{array}$ & M.12 & $\begin{array}{l}\text { Number of His+ } \\
\text { revertants/plate in } \\
\text { 2end test }\end{array}$ & M.11 & $\begin{array}{l}\text { Number of His+ } \\
\text { revertants/plate in 1st } \\
\text { test }\end{array}$ & Zones & Sample \\
\hline & $>800$ & & $>800$ & & $>800$ & & P.C \\
\hline & 115 & & 400 & & 78 & & N.C \\
\hline 2.35 & 271 & 0.2 & 83 & 0.63 & 49 & & 1 \\
\hline 1.25 & 144 & 0.24 & 97 & 1.04 & 81 & 1 & 2 \\
\hline $1.83 *$ & 211 & 0.36 & 146 & 1.02 & 80 & & 3 \\
\hline 1.63 & 188 & 0.19 & 77 & 0.92 & 72 & & 4 \\
\hline 1.33 & 153 & 0.21 & 86 & 1.08 & 85 & 2 & 5 \\
\hline 1.66 & 191 & 0.2 & 82 & 1 & 78 & & 6 \\
\hline 1.37 & 158 & 0.22 & 88 & 0.82 & 64 & & 7 \\
\hline 1.41 & 162 & 0.45 & 182 & 0.68 & 53 & 3 & 8 \\
\hline 1.42 & 163 & 0.17 & 71 & 0.82 & 64 & & 9 \\
\hline 1.57 & 181 & 0.19 & 78 & 0.76 & 59 & & 10 \\
\hline 1.64 & 189 & 0.21 & 84 & 0.72 & 56 & 4 & 11 \\
\hline 1.41 & 162 & 0.25 & 103 & 1.07 & 84 & & 12 \\
\hline 1.32 & 152 & 0.14 & 58 & 0.97 & 76 & & 13 \\
\hline 1.6 & 185 & 0.18 & 75 & 0.84 & 66 & 5 & 14 \\
\hline 1.47 & 169 & 0.15 & 61 & 0.73 & 57 & & 15 \\
\hline
\end{tabular}

P. C: Positive Control; N.C: Negative Control; *Mutagenic Index (M.I.) = (The number of revertant colonies in the sample plate $) /($ The number of colonies in the negative control plate)

Table 4. Ames Mutagenicity Assay on Tea Bag Samples Using YG1029strain

\begin{tabular}{|c|c|c|c|c|c|c|}
\hline M.1C & $\begin{array}{l}\text { Number of His+ } \\
\text { revertants/plate }\end{array}$ & M.IB & $\begin{array}{l}\text { Number of His+ } \\
\text { revertants/plate }\end{array}$ & M.IA & $\begin{array}{l}\text { Number of His+ } \\
\text { revertants/plate }\end{array}$ & Sample \\
\hline & In sample $\mathrm{C}$ & & In sample B & & in sample A & \\
\hline & $>800$ & & $>800$ & & $>800$ & P.C \\
\hline & 119 & & 172 & & 111 & N.C \\
\hline \multicolumn{7}{|c|}{ After 5 minutes in RT } \\
\hline 1.02 & 84 & 1.26 & 181 & 0.93 & 103 & 1 \\
\hline 0.79 & 65 & 1.24 & 178 & 0.78 & 87 & 2 \\
\hline 0.78 & 64 & 1.16 & 167 & 1.14 & 127 & 3 \\
\hline \multicolumn{7}{|c|}{ After 10 minutes in $\mathrm{RT}$} \\
\hline 0.8 & 66 & $2 * *$ & 288 & 0.83 & 92 & 4 \\
\hline 0.81 & 67 & $1.87^{*}$ & 270 & 0.76 & 85 & 5 \\
\hline 0.75 & 62 & $1.84 *$ & 265 & 1.4 & 156 & 6 \\
\hline \multicolumn{7}{|c|}{ After 15 minutes in $\mathrm{RT}$} \\
\hline 0.91 & 75 & $1.87 *$ & 270 & $2.11 * *$ & 235 & 7 \\
\hline 1.06 & 87 & 1 & 144 & 1.05 & 117 & 8 \\
\hline 0.82 & 67 & $1.87 *$ & 269 & 1.22 & 136 & 9 \\
\hline
\end{tabular}

P. C: Positive Control; N.C: Negative Control; *: possible mutagenic potential is assumed ; **: mutagenic potential is assumed; *Mutagenic Index $($ M.I. $)=($ The number of revertant colonies in the sample plate $) /($ The number of colonies in the negative control plate $)$

YG1029 strains in the autumn 2014 except one water sample with possible mutagenic potential $(\mathrm{MI}=1.83)$ therefore none of the water samples were considered as mutagen in the autumn 2014 (table 3). Details on TA100 and WG1029 bioassays were not showed.
Mutagenic potentials of tea bags by Ames test

Although TA 98 and TA 100 didn't show any mutagenic effect in the test samples of our three evaluated brands, tea bag B from a local company showed possible mutagenic to mutagenic potentials in YG1029 strains clearly. In fact after remaining the black tea bags for 10-15 minutes in 
boiled tap water( as a routine method of tea preparation) most of samples were considered as possible mutagen or mutagen in brands B (Table 4).

\section{Discussion}

Black Tea is one of the most widely consumed beverage in the world with health promoting properties (Rezaee et al., 2014), (Jain et al., 2013) but residues of certain toxicants in different tea samples might impose a health threat on tea drinkers (Ciemniak et al., 2010). It has been clarified that higher amounts of catechins, caffeine, and gallic acid could be released from tea bags using hot water during prolonged steeping (Yang et al., 2007). Moreover some recent studies in Asian countries showed the association between black tea consumption and increased risk of renal cell carcinoma (Washio $M$ et al., 2014), gastric cancer (Tong et al., 2014) and pancreatic cancer (Liu et al., 2014). We hypothesized in this study that some mutagenic colorants and flavoring agents could be released during steeping time from flavored brands of black tea. Our preliminary results have demonstrated that drinking water samples from 5 different zones of Tehran in autumn and summer was not mutagenic towards $\mathrm{S}$. typhimurium strains TA100, TA 98 and YG1029 when tested in the absence of S9 fraction. This part of study indicated that no direct-acting mutagen causes base-pair substitution in these three strains and this type of mutagens could not be detected in drinking water of evaluated regions of Tehran. Although results for water samples were negative to mutagens in all three salmonella strains, one of regional tea samples, showed possible mutagenic effects using YG1029 strain when the steeping duration prolonged to 10 and 15 minutes with drinking water of Tehran.

Some studies have indicated that tea flower extract does not have any mutagenic potential, and its acute and subchronic toxicity towards animals is also negligible (Li et al., 2011). In addition significant antimutagenic activities on bacterial strains and anticancer activities on bacterial and mammalian cells have been reported for Darjeeling tea as one of the most popular variety of black tea (Bhattacharya et al., 2014). A black tea product showed a cancer preventive activity compared with the untreated control in mice by in vivo buccal mucosa Micronucleus test (Qian et al., 2013). Despite these impressive finding about black tea, some recent investigations showed that the plant (Camellia sinensis) may contain trace metals such as copper $(\mathrm{Cu})$, chromium $(\mathrm{Cr})$, manganese $(\mathrm{Mn})$, iron $(\mathrm{Fe})$ and nickel (Ni) as well as heavy metals such as arsenic (As), lead ( $\mathrm{Pb})$ and mercury $(\mathrm{Hg})$, which could be present within the impermissible limits (Nema et al., 2014). Some reports showed the existence of heavy metals, fluoride, pesticides, dioxins and aflatoxines in some Iranian tea samples (Pouretedal et al., 2013). Tea lives which possess a high surface area in polluted areas can be contaminated with atmospheric PAHs and other toxicants and high risk manufacturing processes may also introduce many toxicants into tea lives (Rezaee et al., 2014) (Ciemniak et al., 2010). It seems that some mutagenic agents could be released from brand $B$ in this study even in the absence of S9 fraction, indicating the possible presence of above direct-acting mutagens causing base-pair substitution inYG1029.

The YG1029 strain has been provided from the insertion of a plasmid carrying the acetyltransferase gene into TA100 strain. Hence this strain (YG1029) overproduce $\mathrm{N}$-hydroxyarylamine $\mathrm{O}$-acetyltransferase enzyme (OAT) which is extremely sensitive to the mutagenic action of typical nitroarenes and aromatic amines which may exist in our flavored tea samples, so it doesn't need any intra- and/or extra-cellular metabolic conversion for interacting with bacterial DNA (Watanabe et al., 1994). Despite the mutagenic potentials of some tea bags additives such as dyes, aromatic substances, pesticides and phenolic components two samples of tea bags didn't show any mutagenic potential when compared with brand $\mathrm{B}$.

As a conclusion it seems that the Ames test even without $\mathrm{s} 9$ fraction is an appropriate method for primary screening of mutagenic effects of some possible chemical compounds in flavored tea bags and YG1029 strain could be considered as a sensitive strain for initial regulatory tests but as aflatoxins has been recently discovered in some black tea samples in Iran it seems necessary to ensure the existence of mutagenic potential of each product as a preliminary test by Ames test using YG1029 as s sensitive strain and analysis the suspected mutagen samples by further analytical methods.

\section{Acknowledgements}

This work has been financially supported by Islamic Azad University, Pharmaceutical Sciences Branch as Pharm D thesis of Farzaneh Alebouieh.

\section{References}

Abda A, Benouareth DE, Tabet M, et al (2015). Mutagenicity and genotoxicity of drinking water in Guelma region, Algeria. Environ Monit Assess, 187, 4223.

Anon (1997). OECD GUIDELINE FOR TESTING OF CHEMICALS, Bacterial Reverse Mutation Test.

Bain R, Cronk R, Wright J, et al (2014). Fecal Contamination of Drinking-Water in Low- and Middle-Income Countries: A Systematic Review and Meta-Analysis. PLoS Med, 11, 1001644.

Bhattacharya U, Adak S, Majumder NS, et al (2014). Antimutagenic and anticancer activity of Darjeeling tea in multiple test systems. BMC Complement Altern Med, 2, 327.

Bidgoli SA, Khorasani H, Keihan H, et al (2012). Role of endocrine disrupting chemicals in the occurrence of benign uterine leiomyomata: special emphasis on AhR tissue levels. Asian Pac J Cancer Prev, 13, 5445-50.

Ciemniak A, Mocek K, (2010). Polycyclic aromatic hydrocarbons in tea and tea infusions. Rocz Panstw Zakl Hig, 61, 243-8.

Dhaini HR, Nassif RM (2014). Exposure assessment of endocrine disruptors in bottled drinking water of Lebanon. Environ Monit Assess, 186, 5655-62.

Doak SH, Manshian B, Jenkins GJ, et al (2012). In vitro genotoxicity testing strategy for nanomaterials and the adaptation of current OECD guidelines. Mutat Res, 745, 104-11.

Ileka-Priouzeau S, Campagna C, Legay C, et al (2015). Women exposure during pregnancy to haloacetaldehydes and haloacetonitriles in drinking water and risk of small-for- 
Farzaneh Alebouyeh et al gestational-age neonate. Environ Res, 137, 338-48.

Jain A, Manghani C, Kohli S, et al (2013). Tea and human health: the dark shadows. Toxicol Lett, 220, 82-7.

Jansson K, Maki-Paakkanen J, Vaittinen SL, et al (1993). Citogenetic effects of 3-chloro-4(dichloromethyl)-5hydroxy$2(5 \mathrm{H})$-furanone $(\mathrm{MX})$ in rat peripheral lymphocytes In Vitro and In Vivo. Mutat Res, 299, 25-8.

Karyab H, Yunesian M, Nasseri S, et al (2013). Polycyclic Aromatic Hydrocarbons in drinking water of Tehran, Iran. $J$ Environ Health Sci Eng, 11, 25.

Mortelmans K, Zeiger E (2000). The Ames Salmonella/ microsome mutagenicity assay. Mutat Res, 455, 29-60.

Kumar A, Pandey AK, Singh SS, et al (2011). Cellular uptake and mutagenic potential of metal oxide nanoparticles in bacterial cells. Chemosphere, 83, 1124-32.

Kusamran WR, Tanthasri N, Meesiripan N, et al (2003). Mutagenicity of the drinking water supply in Bangkok. Asian Pac J Cancer Prev, 4, 31-8.

Li B, Jin Y, Xu Y, et al (2011). Safety evaluation of tea (Camellia sinensis (L.O. Kuntze) flower extract: assessment of mutagenicity, and acute and subchronic toxicity in rats. $J$ Ethnopharmacol, 133, 583-90.

Liu SZ, Chen WQ, Wang N, et al (2014). Dietary factors and risk of pancreatic cancer: a multi-centre case-control study in China. Asian Pac J Cancer Prev, 15, 7947-50.

Li Y, Chen DH, Yan J, et al (2012). Genotoxicity of silver nanoparticles evaluated using the Ames test and in vitro micronucleus assay. Mutat Res, 745, 4-10.

Lupi S, Marconi S, Paiaro E, et al (2009). Mutagenicity evaluation with Ames test of hydro-alcoholic solution of terpenes. J Prev Med Hyg, 50, 170-4.

Kumari M, Gupta SK, Mishra BK( 2015). Multi-exposure cancer and non-cancer risk assessment of trihalomethanes in drinking water supplies - A case study of Eastern region of India. Ecotoxicol Environ Saf, 113, 433-8.

Nema NK, Maity N, Sarkar BK, et al (2014). Determination of trace and heavy metals in some commonly used medicinal herbs in Ayurveda. Toxicol Ind Health, 30, 964-8.

Pongpiachan S, Choochuay C, Hattayanone M, et al (2013). Temporal and spatial distribution of particulate carcinogens and mutagens in Bangkok, Thailand. Asian Pac J Cancer Prev, 14, 1879-87.

Pouretedal Z, Mazaheri M (2013). Aflatoxins in black tea in Iran. Food Addit Contam Part B Surveill, 6, 127-9.

Punvittayagul C, Sringarm K, Chaiyasut C, et al (2014). Mutagenicity and antimutagenicity of hydrophilic and lipophilic extracts of Thai northern purple rice. Asian Pac J Cancer Prev, 15, 9517-22.

Qian Y, Zhu K, Wang Q, et al (2013). Antimutagenic activity and preventive effect of black tea on buccal mucosa cancer. Oncol Lett, 6, 595-9.

Rezaee E, Mirlohi M, Fallah A, et al (2014). A systematic review on exposure to toxic and essential elements through black tea consumption in iran: could it be a major risk for human health? Int J Prev Med, 5, 1351-9.

Rincon-Bedoya E, Velasquez N, Quijano J, et al (2013). Mutagenicity and genotoxicity of water treated for human consumption induced by chlorination by-products. J Environ Health, 75, 28-36.

Sato G, Asakura S, Hakura A, et al (2000). Assessment of potential mutagenic activities of a novel benzothiazole MAO-A inhibitor E2011 using Salmonella typhimurium YG1029. Mutat Res, 472, 163-9.

Tong GX, Liang H, Chai J, et al (2014). Association of risk of gastric cancer and consumption of tobacco, alcohol and tea in the Chinese population. Asian Pac J Cancer Prev, 15, 8765-74.
Villanueva CM, Font-Ribera L (2012) Health impact of disinfection by-products in swimming pools. Ann Ist Super Sanita, 48, 387-96.

Villanueva CM, Kogevinas M, Cordier S, et al (2014). Assessing exposure and health consequences of chemicals in drinking water: current state of knowledge and research needs. Environ Health Perspect, 122, 213-21.

Washio M, Mori M, Mikami K, et al (2014). Risk factors for renal cell carcinoma in a Japanese population. Asian Pac J Cancer Prev, 15, 9065-70.

Watanabe M, Igarashi T, Kaminuma T, et al (1994). N-hydroxyarylamine O-acetyltransferase of Salmonella typhimurium: proposal for a common catalytic mechanism of arylamine acetyltransferase enzymes. Environ Health Perspect, 102, 83-89.

Water quality -- Sampling -- Part 1: Guidance on the design of sampling programmes and sampling techniques. s.1.:International standard.

Wright JM, Schwartz J, Vartiainen T, et al (2002). 3-chloro4(dichloromethyl)-5-hydroxy-2(5H)-furanon(MX) and mutagenic activity in massachusetts drinking water. Environ Health Perspect, 110, 157-64.

Yang DJ, Hwang LS, Lin JT (2007). Effects of different steeping methods and storage on caffeine, catechins and gallic acid in bag tea infusions. J Chromatogr A, 1156, 312-20.

Ziarati P, Bidgoli SA (2012). Evaluation of the nitrate content in leafy vegetables of southern parts of tehran: a four seasonal study. Scientificreports, 165, 1.

Zhao L, Liu CL, Song QK, et al (2014). Association between dietary behavior and esophageal squamous cell carcinoma in Yanting. Asian Pac J Cancer Prev, 15, 8657-60. 